\title{
A Novel Approach for Disposing Agriculture Waste, Minimizing Air Pollution and Amending Soil Through Biochar Production and Application
}

\author{
M. P. Choudhary*†, H. D. Charan** and B. Acharya* \\ *Department of Civil Engineering, Rajasthan Technical University, Kota-324 010, India \\ **Bikaner Technical University, Bikaner-334 004, India \\ †Corresponding author: M. P. Choudhary; choudhary_mp@yahoo.co.in
}

Nat. Env. \& Poll. Tech.

Website: www.neptjournal.com

Received: 29-03-2020

Revised: 26-05-2020

Accepted: 03-06-2020

\section{Key Words:}

Biochar

Crop residues

Soil properties

Greenhouse gas

Climate change

\begin{abstract}
The burning of crop residues (traditionally called 'Parali') has recently become a hot topic in India because it is presumed to be one of the reasons for abnormally high levels of air pollution in New Delhi, the capital city of India, after harvesting of Kharif crops during winter months. During the process of finding out a feasible solution for quick disposal of agricultural waste in a safer way, a novel method has been developed by the authors in which crop residue is converted into a useful product, biochar, which can be applied back to the fields for amendment of soil. It not only reduces the introduction of harmful gases into the environment but also improves the physical and chemical properties of the soil. This method is very simple and can be adopted by an individual farmer without much investment and technical skills. Many studies have been conducted on the factors involved in the production and use of biochar as a soil amendment; but in India, not much work has been carried out yet, as it is relatively a new concept in terms of using biomass for biochar production and application. Although biochar is not a new product, it has drawn the attention of researchers and other stakeholders in the near past because of its usefulness in improving the physical and chemical properties of the soil and at the same time reducing greenhouse gas emission, which is one of the biggest challenges for the modern world to protect the environment.
\end{abstract}

\section{INTRODUCTION}

It has been noticed that the capital city of India, New Delhi is facing a severe problem of air pollution for some years during the winter season when harvesting of Kharif crops takes place in Delhi and nearby states like Punjab, Haryana, Rajasthan, Uttar Pradesh and Madhya Pradesh.

The yearly outbreak of smog during the months of October-November in New Delhi is known to occur due to open burning of crop residues by the farmers of the nearby States. The severity of the problem can easily be understood with an example when New Delhi witnessed the worst category of air quality index in winter 2017. During this period, the concentration of fine particulate matter $\left(\mathrm{PM}_{2.5}\right)$ was observed at the highest level ever at $640 \mu \mathrm{g} / \mathrm{m}^{3}$ (ETB 2017) against the annual permissible limits of $40 \mu \mathrm{g} / \mathrm{m}^{3}$ prescribed by the national ambient air quality standards of India (NAAQS 2009). This situation has arisen recently because the Indian farmers have started making use of modern harvesters and crop cutters which cut only the useful upper part of the crops like rice and millet and bottom parts are left behind on the fields which are further set on fire by the farmers to prepare the fields for the next Rabi crops in a shorter period and without any cost. Fig. 1 shows an agriculture field near Kota, Rajasthan in which crop residues are set to fire by the farmer. Although, the National Green Tribunal (NGT), New Delhi has imposed a ban on the open burning of crop residues in the country in 2015 (DTE 2015) still Indian farmers are not abiding by it in its strict sense. A large generation of agriculture waste further aggravates the situation. According to the Ministry of New and Renewable Energy (MNRE), Govt. of India, about 500 Million Tons (MT) of crop residue is generated every year out of which about 92 MT is directly burned in the fields (NPMCR 2014).

There are studies available in the literature highlighting factors involved in the production and use of biochar for soil amendment (Barus 2016, Carter et al. 2013, Ding et al. 2016, Gokila \& Baskar 2015, Lydia \& Rianne 2015, Parmar et al. 2014, Tammeorg et al. 2017); but in India, not much work has been carried out yet, as it is relatively a new concept in terms of using crop residues for the production of biochar and its application. Therefore, it was decided to carry out a study in which a novel and easy method of biochar production from crop residues is found out and the consequences of applying biochar as soil improvement are studied. 


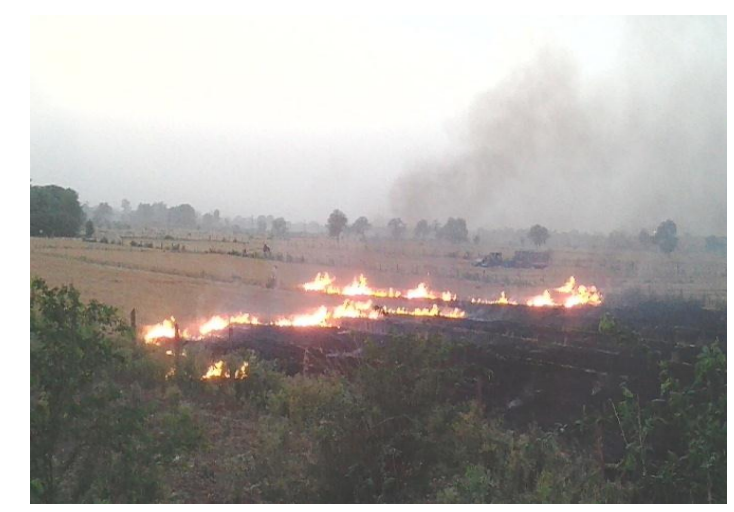

Fig.1: Crop residues set to fire in a field near Kota, Rajasthan.

\section{MATERIALS AND METHODS}

\section{Biochar}

Biochar is a carbon-rich product formed by a process called pyrolysis, in which the biomass is heated either in the absence of or with a limited amount of oxygen at a temperature above $250^{\circ} \mathrm{C}$. An extensive range of feedstock biomasses had been employed for producing biochar like wastes of organic nature, agriculture, kitchen, residues of trees and forests, bio-energy crops and even sewage sludge also (Nartey \& Zhao 2014). The properties of each biomass feedstock like ash and moisture content, calorific value, mass, density and particle size are different and hence the produced biochar also have different physical and chemical characteristics (Shareef \& Zhao 2014).

The important characteristics of biochar are $\mathrm{pH}$, ash, surface area, volatiles and water holding capacity, bulk density and pore-volume (Shareef \& Zhao 2014). The exclusive property of biochar is its high porosity which increases the capacity of water and nutrient retention. Also, a large number of pores in biochar offer a favourable environment for soil bacteria by protecting them against drying and predation (Das et al. 2016).

Biochar had been motivated by the intriguing properties of ancient Terra Preta, originated from Amazon basin. It has been identified as a soil amendment and has very specific properties of adsorption and stability that make it unique among organic soil amendments (Lehmann 2007). Recently, biochar has gained more attention because the production of biochar and its presence/storage in soils has been recommended as a way of extenuating climate change by impounding carbon and at the same time providing energy and increased crop yields (Woolf et al. 2010). It has been reported that biochar remains in the soil for a very long time because the mass of the material opposes to the decomposition by microorganisms. During pyrolysis, the molecular biomass configuration is transformed into a stable type and the atmospheric carbon gets combined with biomass and when plants are pyrolyzed, biochar is placed in soil (Shareef $\&$ Zhao 2014). Hence, biochar acts as a tool to sequester carbon in the soil.

\section{Production of Biochar}

Production of carbon-affluent product, biochar is carried out through a process known as pyrolysis, wherein heating of biomass or any other organic substance takes place either in the absence of or with a limited amount of oxygen at temperatures above $250^{\circ} \mathrm{C}$ (Lehmann 2007). The charcoal is also made with the same process but biochar is altogether taken as a different product than charcoal and other carbon products in that it is used as a soil amendment (Lehmann $\&$ Stephen 2015). In recent times, biochar has drawn more attention due to its scope and role in the alleviation of climate change and potential for soil amendment and sustainable cultivation (Lehmann et al. 2011).

Biochar can also be produced from waste materials including those that may otherwise produce even more harmful greenhouse gases (e.g., manure or green wastes) (Lehmann $\&$ Stephen 2015). So, it is beneficial to make use of waste materials in a useful manner and safe disposal at the same time. Biochar can be prepared from locally available weed biomass also, which will reduce the weed mass in the fields on one hand and on the other, it will enhance the growth of plants by improving the physical, chemical and biological characteristics of soil and hence contributing to increased crop yield (Das et al. 2016).

Production of biochar can be carried out either at an individual field by a farmer or in industrial setups (Lehmann \& Stephen 2015, Woolf et al. 2010), making it significant for a large number of socio-economic conditions. Different types of pyrolysis techniques are available at a commercial level which yields varying amounts of biochar and associated bioenergy products like syngas and bio-oil (Woolf et al. 2010). The biomass can be pyrolyzed in a reactor through gasification or carbonization at different temperature and time depending on the final anticipated use of the end product (Ogbonnaya \& Semple 2013). Biochar obtained at high temperatures $\left(500^{\circ} \mathrm{C}\right)$ has been found suitable for direct use as a fuel because of high contents of carbon, retention time, $\mathrm{pH}$ and electrical conductivity whereas biochar obtained at low temperatures $\left(300\right.$ to $350^{\circ} \mathrm{C}$ ) are found appropriate for land application (Singh et al. 2015).

\section{A Novel Method of Biochar Production}

For Indian conditions, biochar can be produced by individual farmers in their fields in conventional kilns made by locally available material or at community kilns by using 
the agricultural wastes and other by-products, so that the biochar produced can be utilized again for applying in the fields for the upcoming crops. A novel method of producing biochar has been developed by the authors wherein the agricultural waste is heated in a drum of capacity 220 litres. The experimental setup of the method is shown in Fig. 2 to Fig. 5.

The biochar produced as above at the field level from agricultural waste is crushed to small pieces, air-dried and

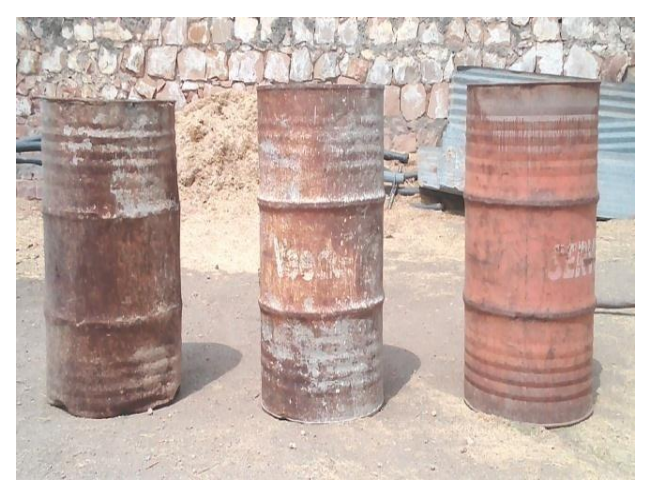

Fig. 2: Drums used for biochar production.

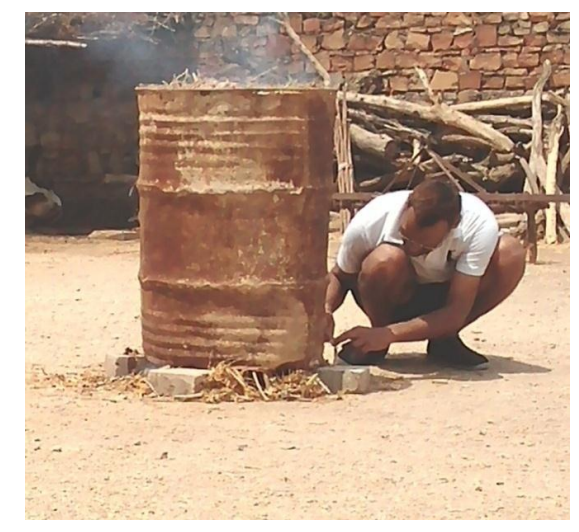

Fig. 4: Igniting the crop residues.

Table 1: Physico-chemical characteristics of Biochar.

\begin{tabular}{|ll|}
\hline Characteristic & Value \\
\hline $\mathrm{pH}$ & 9.8 \\
Moisture (\%) & 8.1 \\
Specific Gravity & 1.62 \\
Electrical Conductivity (mS/cm) & 5.12 \\
Grain Size Distribution (\% Retained) \\
2 mm-4.75 mm (Coarse) & 23.6 \\
0.425 mm-2 mm (Medium) & 46.2 \\
0.075 mm-0.425 mm (Fine) & 30.2 \\
\hline
\end{tabular}

passed through a $4.75 \mathrm{~mm}$ size sieve to get the uniform size of biochar. The important characteristics of biochar like grain size distribution, $\mathrm{pH}$, moisture content, specific gravity and electrical conductivity were determined in the laboratory as per the standard methods (IS: 2720, 2015) and results are presented in Table 1.

\section{Soil Sample and Characteristics}

The soil samples were collected from the agricultural fields

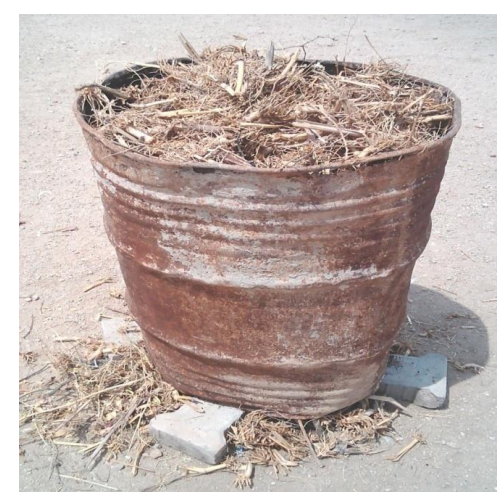

Fig. 3: Drum filled with crop residues.

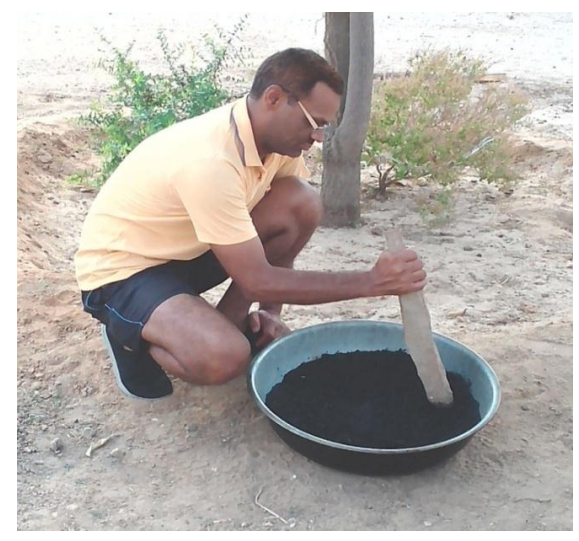

Fig. 5: Biochar produced in the drum is crushed to small pieces.

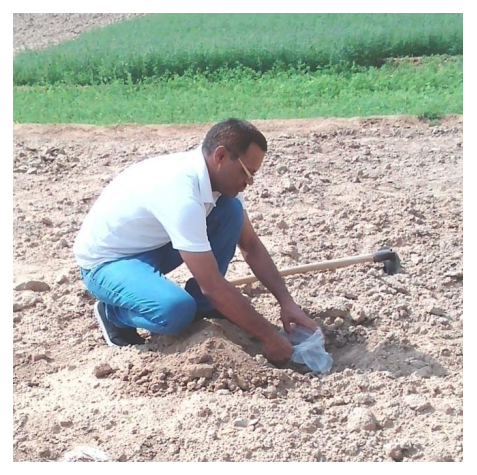

Fig. 6: Collecting soil sample from a field. 
of village Kosana in district Jodhpur, Rajasthan, India. The samples were prepared for tests as per the IS: 2720 (Part1)-1983 in the geotechnical engineering laboratory of the Department of Civil Engineering, Rajasthan Technical University, Kota, India. Fig. 6 shows the collection of the soil sample from field whereas Fig. 7 to Fig. 10 show arrangements for different laboratory tests.

First of all, the soil samples were oven-dried, pulverized and then sieved through $4.75 \mathrm{~mm}$ size sieve to decide about the soil classification. The sieve size analysis resulted into constituents of soil as $69 \%$ of sand, $16.2 \%$ of silt and $14.8 \%$ of clay and hence the soil sample was classified as SC (Clayey Sand) as per the Unified Soil Classification System (USCS). Table 2 represents a summary

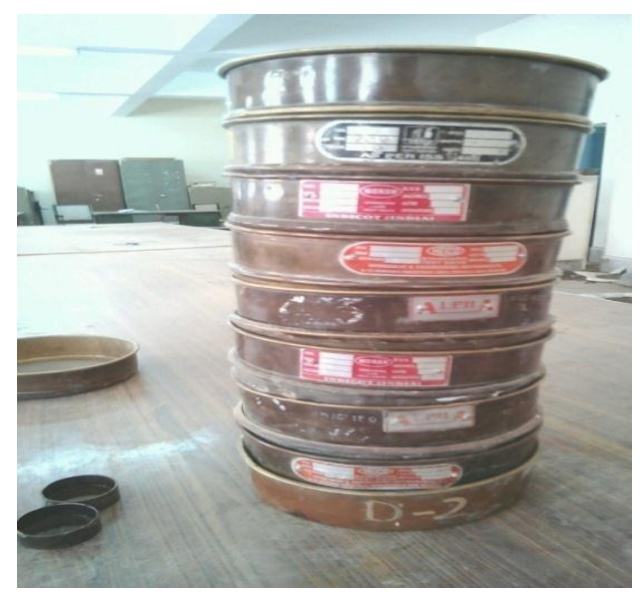

Fig. 7: Sieve set used for particle size analysis.

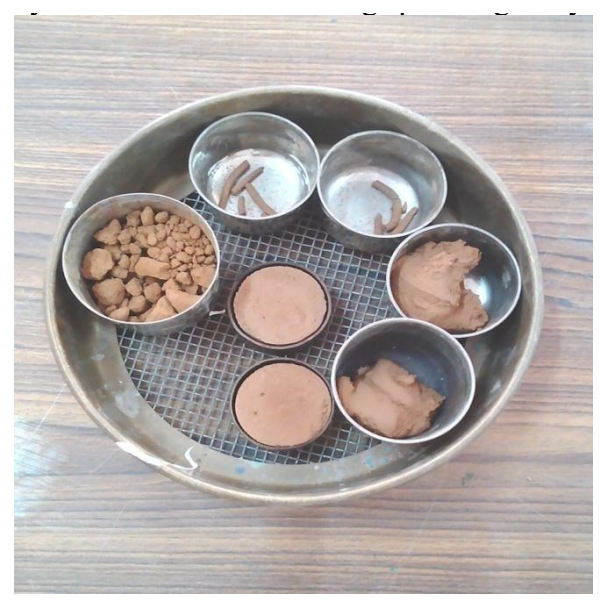

Fig. 9: Soil samples prepared for finding Atterberg limits. of the main physical characteristics of soil and Fig. 11 shows the grain size distribution curve of the soil sample and biochar.

The Atterberg limits of the soil sample were found out. It was observed that liquid limit; plastic limit and shrinkage limit of the soil were $39 \%, 19 \%$ and $15 \%$ respectively.

\section{Biochar as Soil Amendment}

The application of biochar to the soil is anticipated as a new technique to set up a major, enduring sink for atmospheric carbon dioxide in global ecosystems. Along with decreasing emissions and escalating the confiscation of greenhouse gases, the biochar production and its use in soils bring direct payback through enhanced soil productiveness and

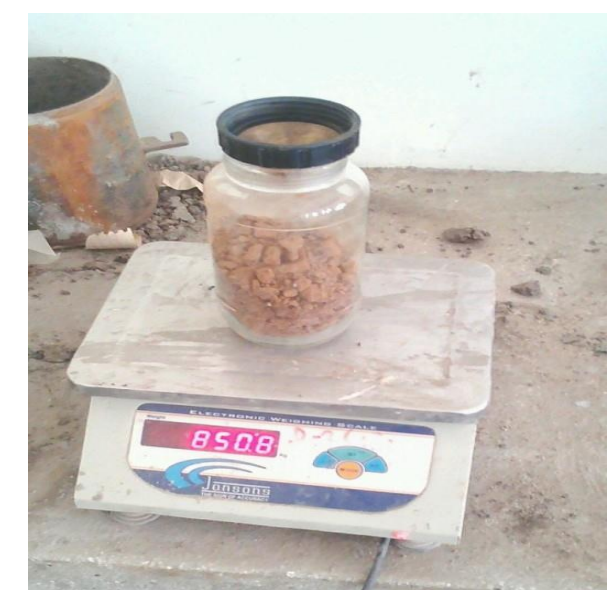

Fig. 8: Pycnometer used for finding specific gravity of soil.

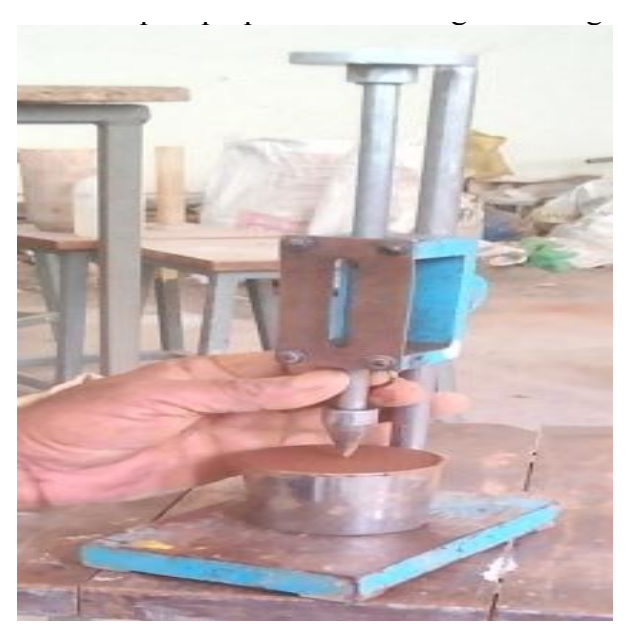

Fig. 10: Cone penetrometer used for finding the liquid limit. 
Table 2: Characteristics of the soil sample.

\begin{tabular}{|c|c|}
\hline Characteristic & Value \\
\hline $\mathrm{pH}$ & 8.2 \\
\hline Specific Gravity & 2.58 \\
\hline Electrical Conductivity $(\mathrm{mS} / \mathrm{cm})$ & 0.94 \\
\hline \multicolumn{2}{|c|}{ Grain Size Distribution (\% Retained) } \\
\hline $2 \mathrm{~mm}-4.75 \mathrm{~mm}$ (Coarse Sand) & 6.0 \\
\hline 0.425 mm-2 mm (Medium Sand) & 30.4 \\
\hline $0.075 \mathrm{~mm}-0.425 \mathrm{~mm}$ (Fine Sand) & 32.6 \\
\hline $0.002 \mathrm{~mm}-0.075 \mathrm{~mm}$ (Silt) & 16.2 \\
\hline$<0.002 \mathrm{~mm}$ (Clay) & 14.8 \\
\hline \multicolumn{2}{|c|}{ Consistency Limits (\%) } \\
\hline Liquid Limit & 39 \\
\hline Plastic Limit & 19 \\
\hline Shrinkage Limit & 15 \\
\hline
\end{tabular}

amplified crop yield as well (Lehmann et al. 2006). Biochar has been acknowledged as a soil amendment and has very explicit properties of adsorption and stability that make it distinctive among organic soil amendments (Lehmann 2007).

Testimonials are available that biochar remains in the soil for a very long time because the mass of the material opposes to the decomposition by microorganisms. During pyrolysis, the molecular biomass configuration is transformed into a stable type and the atmospheric carbon gets combined with biomass and when plants are pyrolyzed, biochar is placed in soil (Shareef \& Zhao 2017). Hence, biochar acts as a tool to confiscate carbon in the soil.

To study the effect of biochar on consistency behaviour of soil, tests were carried out to find out the liquid limit, plastic limit and shrinkage limit of the soil amended with different per cent by weight ( $\% \mathrm{w} / \mathrm{w})$ of biochar like $5 \%, 10 \%, 15 \%$, $20 \%$ and $25 \%$. For this purpose, the biochar was added in dry condition to the soil and the soil-biochar mix was thoroughly mixed. The tests of consistency limits were performed as per the standard methods (IS: 2720, 2015).

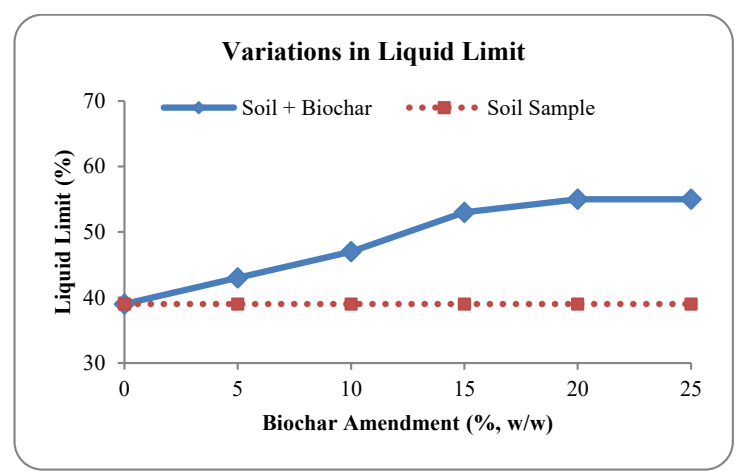

Fig. 12: Effect of Biochar amendment on the liquid limit of soil.

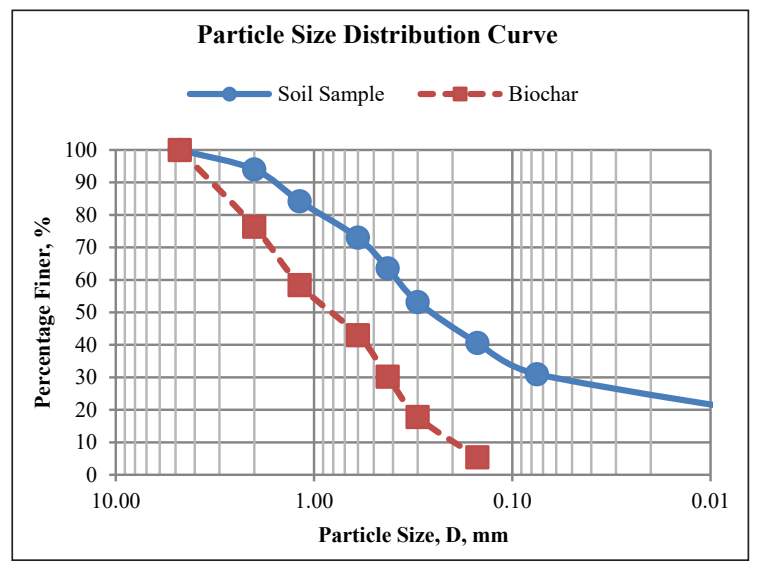

Fig. 11: Grain size distribution curve of the soil sample and Biochar.

\section{RESULTS AND DISCUSSION}

The result of the biochar amendment on the liquid limit of the soil is shown in Fig. 12. It was found that liquid limit of the soil amended with biochar increased from $39 \%$ to $43 \%, 47 \%, 53 \%, 55 \%$ and remained constant at $55 \%$ on addition of biochar at $5 \%, 10 \%, 15 \% 20 \%$ and $25 \%(\mathrm{w} / \mathrm{w})$ respectively. It can be inferred from the results that liquid limit of the soil increases with adding up of biochar into it up to a certain point because biochar has high porosity and surface area which increases the liquid limit of the soil-biochar composite.

Fig. 13 shows the effect of biochar amendment on the plastic limit of the soil. It was observed that plastic limit of the soil-biochar composite increased from $19 \%$ to $24 \%$ when $5 \%$ biochar (w/w) was added to the soil and thereafter it slowly increased for $10 \%$ and $15 \%$ and remained constant at $20 \%$ addition of biochar. Further, it was not possible to find the plastic limit of the soil-biochar composite at $25 \%(\mathrm{w} / \mathrm{w})$ biochar amendment because the composite did not show any plastic behaviour. It crumbled at higher water contents. Hence, we can infer that the initial increase in plastic limit is

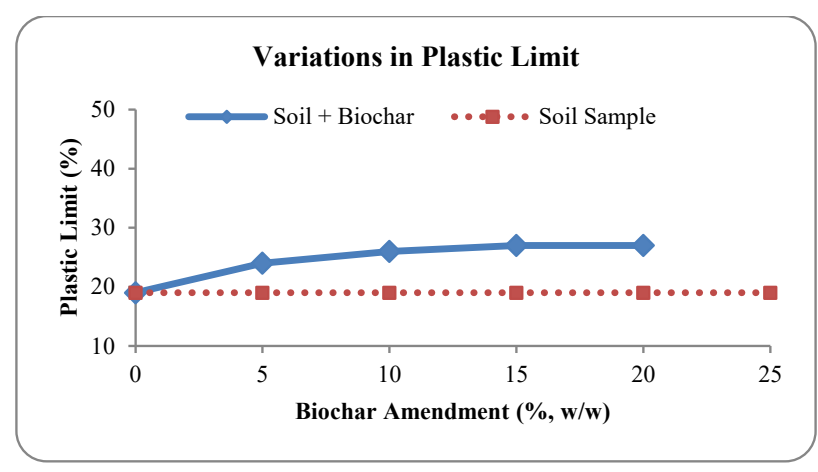

Fig. 13: Effect of Biochar amendment on the plastic limit of soil. 


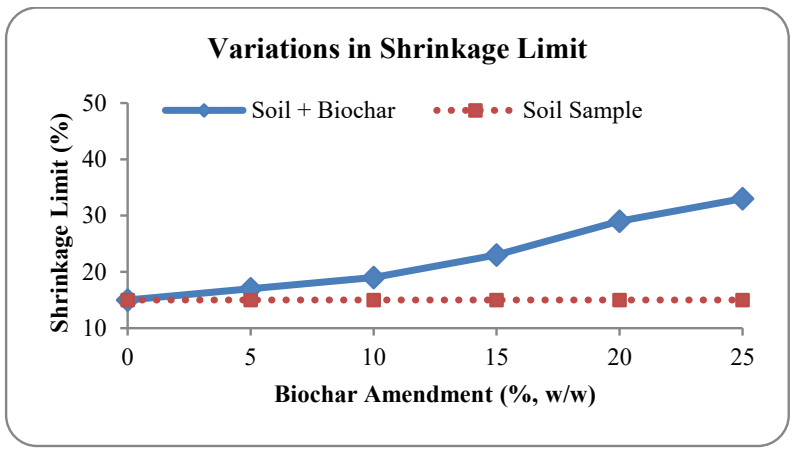

Fig. 14: Effect of Biochar amendment on shrinkage limit of the soil.

because of the water absorbing capacity of the soil-biochar composite up to a certain limit.

Fig. 14 shows the variations in shrinkage limit of the soil amended with biochar at different ratios. The initial increase in shrinkage limit up to $10 \%$ addition of biochar is slightly slow but thereafter it goes up sharply up to $25 \%$ (w/w). The increase can be seen from $15 \%$ in the soil sample to $17 \%$, $19 \%, 23 \%, 29 \%$ and $33 \%$ respectively in the soil-biochar composite. The increase in shrinkage limit indicates that there is a higher void ratio in the biochar as compared to soil and hence soil amended with biochar requires more amount of water to change from solid-state to semi-solid state.

Thus, we can see that the consistency limits have increased upon adding up of biochar to the soil up to a certain per cent by weight and therefore, the physical properties of the soil are improved, which supports and verifies the hypothesis available in the literature that biochar can act as a soil amendment and in the Indian context, it has good potential due to large quantities of crop residues generated every year.

\section{CONCLUSIONS}

The present study reveals that biochar can easily be produced at an individual level in the fields after harvesting is over by utilizing the crop residues without much cost and time. The technique of producing biochar is very simple and needs no particular technical knowledge and skill. The study showed that the amendment of soil with biochar in different per cent by weight has sound effects on the consistency behaviour of the soil. The liquid limit, plastic limit and shrinkage limit of the soil amended with biochar increases up to a certain point. Hence, we can conclude that if the Indian farmers start producing and using biochar in their agricultural fields, the agricultural waste, which has otherwise no utility, has a very good potential of disposal and management by conversion into biochar, improving the soil properties when applied in fields and at the same time reducing the level of air pol- lution and greenhouse gases, especially in New Delhi and the country as a whole. It can be termed as a single panacea for environmental protection in which agricultural waste is utilized, soil amendment is achieved and air pollution is controlled.

\section{REFERENCES}

Barus, J. 2016. Utilization of crops residues as compost and biochar for improving soil physical properties and upland rice productivity. J. Degraded Mining Lands Manage., 3(4): 631-637.

Carter, S., Shackley, S., Sohi, S., Suy, T.B. and Haefele, S. 2013. The impact of biochar application on soil properties and plant growth of pot grown lettuce (Lactuca sativa) and cabbage (Brassica chinensis). Agronomy, 3: 404-418.

Das, S.K., Avasthe, R.K. and Matber Singh. 2016. Carbon-negative biochar from weed biomass for agricultural research in India. Curr. Sci., 110(11): 2045-2046.

Ding, Y., Liu, Y., Liu, S., Li, Z., Tan, X., Huang, X., Zeng, G., Zhou, L. and Zheng, B. 2016. Biochar to improve soil fertility: A review. Agron. Sustain. Dev., 36 :36. https://doi.org/10.1007/s13593-016-0372-z.

DTE (Down To Earth) 2015. https://www.downtoearth.org.in/news/air/ paddy-burning-ngt-orders-fine-imposition-on-erring-farmers-51698. Accessed 18 March 2020,

ETB (Economics Times Bureau) 2017. Odd-even plan for five days in Delhi from Monday.https://economictimes.indiatimes.com/news/ politics-and-nation/odd-even-plan-for-five-days-in-delhi-from-monday/ articleshow/61575418.cms, Accessed 18 March 2020.

Gokila, B. and Baskar, K. 2015. Influence of biochar as a soil amendment on yield and quality of maize in alfisols of Thoothukudi district of Tamilnadu, India. Int. J. Plant, Animal Env. Sci., 5(1): 152-155.

Indian Standards (IS): 2720 2015. Method of Tests for Soils, various parts published by Bureau of Indian Standards, New Delhi.

Lehmann, J. 2007. Bio-energy in the black. Frontiers Ecol. Env., 5: 381-387.

Lehmann, J. and Stephen Joseph 2015. Biochar for Environmental Management: Sci. Tech. Implementation. $2^{\text {nd }}$ edn. Routledge, London.

Lehmann, J., Gaunt, J. and Rondon, M. 2006. Bio-char sequestration in terrestrial ecosystems- A review. Mitigation Adaptation Strategies for Global Change, 11: 403-427.

Lehmann, J., Rillig Matthias, C., Janice Thies, Masiello Caroline, A., Hockaday William, C. and Crowley David 2011. Biochar effects on soil biota- A review. Soil Biol. Biochem., 43(9): 1812-1836.

Lehmann Johannes. 2007. A handful of carbon. Nature, 447: 143-144.

Lydia Fryda and Rianne Visser 2015. Biochar for soil improvement: Evaluation of biochar from gasification and slow pyrolysis. Agric., 5: 1076-1115.

NAAQS (National Ambient Air Quality Standards) 2009. Central Pollution Control Board, India. http://www.moef.nic.in/sites/default/files/ notification/Recved\%20national.pdf, Accessed 18 March 2020.

Nartey, D., Obemah and Zhao Baowei 2014. Biochar preparation, characterization, and adsorptive capacity and its effect on bioavailability of contaminants: An overview. Advances in Materials Sci. Eng., http:// dx.doi.org/10.1155/2014/715398.

NPMCR (National Policy for Management of Crop Residues) 2014. Available online: http://agricoop.nic.in/sites/default/files/NPMCR_1.pdf, Accessed 18 March 2020.

Ogbonnaya, Uchenna and Semple T. Kirk 2013. Impact of biochar on organic contaminants in soil: A tool for mitigating risk. Agronomy, 3: 349-375.

Parmar, Aditya, Nema Prabhat, K. and Agarwal, Tripti 2014. Biochar production from agro-food industry residues: a sustainable approach for soil and environmental management. Curr. Sci., 107(10): 1673-1682. 
Shareef, T. M. E. and Zhao, B. W. 2017. The fundamentals of biochar as a soil amendment tool and management in agriculture scope: an overview for farmers and gardeners. J. Agric. Chem. Env., 6: 38-61.

Singh, Anita, Biswas, A.K., Singh Rashmi, Lakaria Brij Lal and Dubey, A.K. 2015. Effect of pyrolysis temperature and retention time on mustard straw-derived biochar for soil amendment. J. Basic. Appl. Sci. Res., 5(9): 31-37.
Tammeorg, Priit, Bastos, Ana Catarina, Jeffery Simon, Rees Frédéric, Kern Jürgen and Graber Ellen, R. 2017. Biochars in soils: Towards the required level of scientific understanding. Journal of Environmental Engineering and Landscape Management, 25(2): 192-207.

Woolf, Dominic, Amonette James, E., Street-Perrott, F., Alayne, Lehmann Johannes and Joseph Stephen 2010. Sustainable biochar to mitigate global climate change. Nat. Commun., 1: 56. 